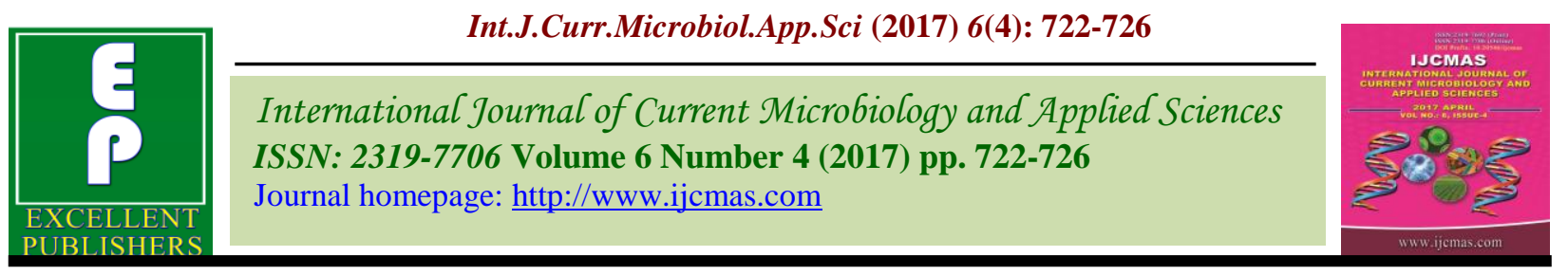

Original Research Article https://doi.org/10.20546/ijcmas.2017.604.088

\title{
Seroprevalence of Hepatitis B Surface Antigen (HBsAg) Among Patients at a Tertiary Care Hospital in Mumbai, India
}

\author{
Hemangi Ingale*, Pranali Medhekar, Nilma Hirani and Abhay Chowdhary \\ Department of Microbiology, Grant Government Medical College and \\ Sir J.J Group of hospitals, Mumbai, India \\ *Corresponding author
}

\begin{abstract}
A B S T R A C T
Keywords

Hepatitis B virus (HBV),

Seroprevalence, Chronic infection.

Article Info

Accepted:

06 March 2017

Available Online:

10 April 2017

Hepatitis B virus (HBV) infection is a global public health problem. There is wide variation in seroprevalence of HBV infection. Majority of these infections are chronic and asymptomatic leading to complications like cirrhosis and hepatocellular carcinoma. Aim of the study is to determine seroprevalence of HBV among patients who were attending a tertiary care hospital at Mumbai and to study their demographic features. Patients attending outpatient Department and inpatient Department who were advised for HBsAg testing were included in the study. HBsAg was detected using the Enzyme linked immunosorbent assay (ELISA). Out of 21,782 patients who were screened for HBsAg, $529(2.42 \%)$ were positive. Among the positive cases, prevalence was highest in the age group of 31-45 years (37\%). Seropositivity was higher in males (70.3\%). Majority of these infections were asymptomatic (55.7\%) and detected during routine screening for operative procedures, dialysis and antenatal care. Surveillance for seroprevalence of HBV is necessary for evaluating vaccination programs and other prevention and control efforts. Early diagnosis of HBV infection can prevent its spread and complications which results from chronic infection.
\end{abstract}

\section{Introduction}

Hepatitis B is a serious public health problem worldwide. It is a major cause of chronic hepatitis, cirrhosis and hepatocellular carcinoma. Globally an estimated 240 million people are chronically infected with hepatitis B and more than 6, 86, 000 people die every year due to its complications. The prevalence of hepatitis B is highest (5-10\%) in sub Saharan Africa and East Asia. In the Middle East and the Indian subcontinent, an estimated $2-5 \%$ of general population is chronically infected (WHO fact sheet, 2016). India comes under the intermediate zone of endemicity as per WHO guidelines (Previsani et al., 2002).
Hepatitis B virus is transmitted by percutaneous or mucosal exposure to infected blood or other body fluids. The most common modes of transmission of infection are perinatal (mother to child), unsafe sexual practices, needle sharing and occupational or health care related (Hou et al., 2005).

Hepatitis B virus infection may result in subclinical or asymptomatic infection, acute self limited hepatitis or fulminant hepatitis. Chronic HBV infection may also develop which can lead to cirrhosis and hepatocellular carcinoma. Development of chronic infection 
depends upon the age of the person at the time of infection. It is $90 \%$ in infected infants, 25 $50 \%$ in children infected between 1 to 5 years of age and 6-10\% in older children and adults (Shepard et al., 2006).

Diagnosis of hepatitis B infection is based on clinical, biochemical, histological and serological findings. A number of viral antigens and their respective antibodies can be detected in serum after infection. Hepatitis B surface antigen (HBsAg) is the first serological marker to appear in acute hepatitis B. It appears in patient's serum usually 2-10 weeks after infection. Its persistence for more than 6 months is a sign of chronic hepatitis (Liang et al., 2009; Kao et al., 2008).

IgM antibody against hepatitis B core antigen (IgM anti-HBc) is usually detected within 1 month after appearance of $\mathrm{HBsAg}$ and indicates a recent hepatitis $B$ infection. It usually disappears within 6 months. IgG anti $\mathrm{HBc}$ remains detectable throughout patients life. Hepatitis B envelope antigen ( $\mathrm{HBeAg}$ ) indicates active replication of Hepatitis B virus and risk of transmission of infection. Antibody to hepatitis B surface antigen (anti HBs) denotes recovery from hepatitis B and confers a long term protective immunity against hepatitis B virus infection (Kao et al., 2008).

The present study aims at determination of current prevalence of HBsAg among patients attending a tertiary care hospital and to evaluate their demographic profiles.

\section{Materials and Methods}

The present study was conducted from May to December 2016 at the Department of Microbiology of a tertiary care hospital in Mumbai, India for detection of $\mathrm{HBsAg}$ in patients visiting outpatient department (OPD) and admitted in wards as a part of preoperative, antenatal and haemodialysis screening and in patients clinically suspected of Hepatitis B virus infection.

Collection of sample: A single blood sample approximately 2-3 $\mathrm{ml}$ was collected from each patient in a plain vaccutainer tube with all aseptic precautions. Sample was allowed to clot at room temperature for about 30 minutes for clot retraction. Serum was separated by centrifugation at a speed of 3000 rpm for 10 minutes and stored up to 72 hours at $2^{0}-8^{0} \mathrm{C}$.

Detection of HBsAg: All sera were tested qualitatively for detection of HBsAg by a sandwich ELISA method using ErbaLisa Hepatitis B kit (Manufactured by TRANSASIA Bio- Medicals Ltd). Interpretation of results as Reactive and Non Reactive for HBsAg was done as per kit literature.

\section{Results and Discussion}

During the study period, 21,782 patients were screened for HBsAg, of that 529 (2.42\%) patients were positive.

Maximum HBsAg positivity was seen in the age group of 31-45 years (Table 1).

Among the positive cases (529), seroprevalence in males $(70.3 \%)$ was higher than females (29.6\%) (Table 2).

Among HBsAg positive patients $(\mathrm{n}=529)$, 234(44.2\%) patients were having clinical signs and symptoms suggestive of infection, while, remaining patients $[\mathrm{n}=295(55.7 \%)]$ were asymptomatic and were detected during routine screening for operative procedures $(n=177)$, dialysis $(n=103)$ and antenatal care $(n=15)$ (Table 3). 
Table.1 Age wise distribution of HBsAg positive cases

\begin{tabular}{|c|c|c|}
\hline Age groups & No of cases & \% \\
\hline$<15$ & 12 & 2.2 \\
\hline $16-30$ & 161 & 30.4 \\
\hline $31-45$ & 196 & 37 \\
\hline $46-60$ & 117 & 22.11 \\
\hline$>60$ & 43 & 8.12 \\
\hline
\end{tabular}

Table.2 Sex wise distribution of HBsAg positive cases

\begin{tabular}{|l|l|l|}
\hline & Number of positive cases & \% \\
\hline Male & 372 & 70.3 \\
\hline Females & 157 & 29.6 \\
\hline
\end{tabular}

Table.3 Distribution of positive cases according to cause of screening for $\mathrm{HBsAg}$

\begin{tabular}{|c|c|c|}
\hline & Number of positive cases & $\%$ of total positive cases \\
\hline Symptomatic patients & 234 & 44.2 \\
\hline $\begin{array}{l}\text { Asymptomatic patients } \\
\text { - } \quad \text { Preoperative } \\
\text { screening }(\mathrm{n}=177) \\
\text { - } \quad \text { Dialysis } \\
\text { screening }(\mathrm{n}=103) \\
\text { - } \quad \text { ANC } \text { screening }(\mathrm{n}=15)\end{array}$ & 295 & 55.7 \\
\hline
\end{tabular}

The prevalence of hepatitis B virus infection differs in different regions of the world. Depending on the proportion of HBsAg seropositive populations, global epidemiology of HBV infection is categorized as high, intermediate and low endemicity. Approximately $45 \%$ of world population lives in areas of high HBV endemicity (Lavanchy et al., 2004).

In highly endemic countries like South East Asia, China and sub Saharan Africa, the HBsAg seroprevalence is greater than or equal to $8 \%$. In countries with intermediate and low endemicity it is $2-7 \%$ and less than
$2 \%$ respectively. Southern Europe, the middle East, and South Asia have an intermediate endemicity while most central and South America have low endemicity (Ott et al., 2012).

In the present study the seroprevalence of HBsAg was found to be $2.42 \%$. This is comparable to other Indian studies by Chakraborty et al., (2.64\%) and Bhatta et al., (2.5\%). Similar studies from Karnataka (Mindolli et al., 2015), Tamilnadu (Vazhavandal et al., 2014) and Rajasthan (Sood et al., 2010) showed seroprevalence as $1.76 \%, 1.61 \%$ and $0.87 \%$ respectively. 
There is wide variation in the prevalence of HBV infection in different regions of the country. These variations may be due to difference in sample size, methodology for demonstration of HBV serological markers, age groups and population studied (Chaudhary, 2004).

In our study, the prevalence of $\mathrm{HBV}$ infection was higher in males $(70.3 \%)$ as compared to females $(29.6 \%)$ and the predominant age group affected was $31-45$ years (37\%). These findings are in concordance with studies by Sood et al., and Datta et al.

The reason for high prevalence in males may be due to habits like multiple sexual partners, unprotected sexual activities, sharing of needles in IV drug abusers and tattooing. However, in females, high immune response helps in clearing of HBV more rapidly and efficiently (Sandhu et al., 2014).

High prevalence of infection in adults may be due to higher chances of exposure to $\mathrm{HBV}$ due to sexual activity.

In our study majority of HBV seropositive cases were asymptomatic (55.7\%) and detected during routine preoperative, dialysis and antenatal care screening.

HBV infection has a dynamic natural history. It may result in asymptomatic infection, acute self limited hepatitis or chronic infection (Shepard et al., 2006). Persons with chronic HBV infection can remain asymptomatic for years. Early identification of persons with chronic HBV infection is necessary to limit its serious consequences like cirrhosis and hepatocellular carcinoma and also to prevent transmission of infection.

Serological testing for HBsAg is the most important way to identify patients with chronic HBV infection. CDC has recommended $\mathrm{HBsAg}$ testing for pregnant women, infants born to $\mathrm{HBsAg}$ positive mothers, household contacts and sex partners of HBV infected persons, persons born in geographical region with $\geq 2 \% \mathrm{HBsAg}$ prevalence, homosexuals, injection drug abusers and persons who have exposure to blood and body fluids like needle stick injuries in healthcare workers and sexual assault (CDC, 2008).

In conclusion the seroprevalence rate of $\mathrm{HBV}$ infection among patients attending a tertiary care hospital in Mumbai is $2.42 \%$ which is comparable to other studies conducted across the country and worldwide. Predominance of infection in males and adult age group could be due to unsafe sexual practices.

This kind of data generated from tertiary care hospitals helps in evaluation of the effectiveness of vaccination programs and formulation of various health care strategies for management and prevention of $\mathrm{HBV}$ infection.

Early detection of infection is important as a majority of patients remain asymptomatic and create a risk for development of chronic carrier states. Such chronic carriers being unaware of their infection continue to transmit the infection to others. Also the complications of chronic infection lead to greater challenges to the health care system.

\section{Acknowledgement}

The authors are thankful to technical staff of Serology section of Department of Microbiology

Conflict of interest: NIL

\section{References}

Bhatta, C.P., Thapa, B, Rana, B.B. 2003. Seroprevalence of Hepatitis B in 
Kathmandu Medical College teaching hospital. Kathmandu Univ. Med. J., 1: 113-16.

Centers for disease control and prevention (CDC). 2008. Recommendations for identification and public health management of persons with chronic hepatitis B virus infection. MMWR, 57(RR08): 1-20.

Chakraborty, A., Pramanik, S.B., Roy, D.S., Sarkar, S., Sengupta, M., Nandi, A. 2015. A sentinel surveillance study on the prevalence of Hepatitis B infection in a tertiary care hospital in eastern India. IOSR-JDMS, 14(2): 74-78.

Chaudhary, A. 2004. Epidemiology of hepatitis $\mathrm{B}$ virus in India. Hep. B. Annual, 1: 17 24.

Dutta, S., Shivanand, P.G., Chatterjee, A. 1994. Prevalence of hepatitis B surface antigen and antibody among hospital admitted patients in Manipal. Indian J. Public Health, 38: 108-12.

Hou, J., Liu, Z., Gu, F. 2005. Epidemiology and prevention of Hepatitis B virus infection. Int. J. Med. Sci., 2(1): 50-57.

Kao, J.H. 2008. Diagnosis of hepatitis B virus infection through serological and virological markers. Exper Rev. Gastroenterol. Hepatol., 2(4): 553-562.

Lavanchy, D. 2004. Hepatitis B virus epidemiology, disease burden, treatment, and current and emerging prevention and control measures. J. Viral Hepat., 11(2).

Liang, T.J. 2009. Hepatitis B: The virus and disease. Hepatol., 49(5 Suppl): S13-S21.
Mindolli, P.B., Salmani, M.P. 2015. Hepatitis B virus seroprevalence among hospital based general population in a tertiary care centre. Int. J. Curr. Microbiol. App. Sci., 4(10): 964-967.

Ott, J.J., Stevens, G.A., Groeger, J., Wiersma, S.T. 2012. Global epidemiology of hepatitis B virus infection: new estimates of age-specific $\mathrm{HBsAg}$ seroprevalence and endemicity. Vacc., 30(12): 2212-9.

Previsani, N., Lavanchy, D. 2002. World Health Organization. Hepatitis (WHO/CDS/CSR/LYO/ 2002.2).

Sandhu, R., Sharma, G. 2014. Prevalence of Hepatitis B surface antigen as a serological marker in $\mathrm{HBV}$ infection. IJPBS, 4(1): 19-24.

Shepard, C.V., Simard, E.P., Finelly, L., Fiore, A.E., Bell, B.P. 2006. Hepatitis B virus infection: Epidemiology and vaccination. Epidemiol. Rev., 28: 112-125.

Sood, S., Malvankar, S. 2010. Seroprevalence of Hepatitis B surface Antigen, Antibodies to Hepatitis $\mathrm{C}$ virus and Humanimmuno deficiency virus ina Hospital based population in Jaipur, Rajasthan. Indian J. Community Med., 35(1): 165-69.

Vazhavandal, G., Vallab, G.B., Uma, A., Chitra, R.P. 2014. Seroprevalence of hepatitis $\mathrm{B}$ virus among patients at a rural tertiary health care centre in south India: a four year study. Int. J. Res. Med. Sci., 2(1): 310-313.

World health organization. 2016. Hepatitis B: World health organization Fact sheet 204.

\section{How to cite this article:}

Hemangi Ingale, Pranali Medhekar, Nilma Hirani, Abhay Chowdhary. 2017. Seroprevalence of Hepatitis B Surface Antigen (HBsAg) Among Patients at a Tertiary Care Hospital in Mumbai, India. Int.J.Curr.Microbiol.App.Sci. 6(4): 722-726. doi: https://doi.org/10.20546/ijcmas.2017.604.088 